\title{
Short- and Long-Term Outcomes of Spontaneous CSF Hypovolemia
}

\author{
Sait Albayram \\ Cerrahpasa Medical School, Istanbul, Turkey
}

Dear Sir,

We read with interest the article by Chung et al. [1]. The authors presented their experience with intracranial hypotension syndrome. We would like to take this opportunity to emphasize the following points.

The authors reported that their study is the largest study to date evaluating shortand long-term outcomes of patients with CSF hypovolemia. They found that epidural blood patch (EBP) treatment resulted in excellent long-term outcomes, with most of these patients achieving complete headache relief at follow-up. There is obviously a significant difference between the literature, our experience and the result of this study. We think that the result of the study is slightly too optimistic. Given these excellent results we are interested to learn some important points. What was the EBP technique used in this study? Did the authors perform EBP under fluoroscopy? How much blood was injected into epidural space? The authors did not mention any transient or persistent complication of EBP. We have seen many patients in our center complaining of back-ache, mostly shortlasting, after EBP. Finally, the number of reports in the literature regarding intracranial hypertension after treatment of intracranial hypotension has recently increased, and we also wonder if the authors observed this complication in their patient group.

\section{Reference}

1 Chung SJ, Kim JS, Lee MC: Syndrome of ce 1 Chung SJ, Lee JH, Im JH, Lee MC: Shortand long-term outcomes of spontaneous CSF hypovolemia. Eur Neurol 2005;54:63-67.

\section{Reply}

\section{S.J. Chung}

Department of Neurology, Asan Medical Center, University of Ulsan College of Medicine, Seoul, South Korea

We thank Dr. Albayram for his interest in our article. He raised concerns regarding the methods and complications of the epidural blood patch (EBP).

EBP has been frequently employed for the treatment of postlumbar puncture headache over the last 4 decades. Although the etiology and clinical manifestations are different between postlumbar puncture headache and spontaneous CSF hypovolemia, EBP has been successfully used for the management of spontaneous CSF hypovolemia because most cases of CSF hypovolemia resulted from spontaneous CSF leaks that typically occurred at the level of the spine.

We previously reported the favorable short-term outcome of spontaneous CSF hypovolemia in patients who received EBP [1]. The effect of EBP on patients with spontaneous CSF hypovolemia has been demonstrated in previous reports [2-4]. Regarding the procedure of EBP, we first determined the level of spine according to the findings of radioisotope cisternography. Thereafter, we performed EBP by locating the epidural space with a needle and then by collecting

\section{KARGER}

Fax +41613061234 E-Mail karger@karger.ch www.karger.com www.karger.com/ene
Sait Albayram, MD

Department of Radiology, Division of Neuroradiology

Cerrahpasa Medical School

TR-34300 Kocamustafapasa, Istanbul (Turkey)

Tel./Fax +90 212586 1586, E-Mail salbayram@hotmail.com 
and injecting autologous blood aseptically. The volume of blood that was injected was 15-20 ml. Fluoroscopy was not used in our patients.

With regard to the adverse effects of EBP, 3 patients showed increased headache after EBP that lasted 1-2 days. We assumed that this transient nonorthostatic headache after EBP was attributed to transient overcompensation of previous intracranial hypotension by EBP $[1,5]$. Some patients had transient discomfort at the spinal level where EBP was done. But there was no permanent side effect related to EBP in our patients [6].

\section{References}

1 Chung SJ, Kim JS, Lee MC: Syndrome of cerebral spinal fluid hypovolemia: clinical and imaging features and outcome. Neurology 2000;55:1321-1327

2 Mokri B: Spontaneous cerebrospinal fluid leaks: from intracranial hypotension to cerebrospinal fluid hypovolemia - evolution of a concept. Mayo Clin Proc 1999;74:11131123.

3 Sencakova D, Mokri B, McClelland RL: The efficacy of epidural blood patch in spontaneous CSF leaks. Neurology 2001;57:1921-1923.

4 Berroir S, Loisel B, Ducros A, Boukobza M, Tzourio C, Valade D, Bousser MG: Early epidural blood patch in spontaneous intracranial hypotension. Neurology 2004;63:1950-1951.
5 Mokri B: Intracranial hypertension after treatment of spontaneous cerebrospinal fluid leaks. Mayo Clin Proc 2002;77:1241-1246.

6 Chung SJ, Lee JH, Im JH, Lee MC: Short- and long-term outcomes of spontaneous CSF hypovolemia. Eur Neurol 2005;54:63-67.

Sun Ju Chung, MD

Department of Neurology

Asan Medical Center

University of Ulsan College of Medicine

388-1, Pungnap-dong, Songpa-gu

Seoul 138-736 (South Korea)

Tel. +82 23010 3988, Fax +82 24744691

E-Mail sjchung@amc.seoul.kr 